target mass than a heavy-liquid bubble chamber like BEBC.

\section{Ninetyeast Ridge not aseismic after all}

from Peter J. Smith

EVERY now and then one is brought up with a jolt as some long-accepted notion is destroyed at a stroke. Ninetyeast Ridge has just proved a case in point. This $4,500 \mathrm{~km}$ long ridge, which dominates the topography of the eastern Indian Ocean, lies roughly along longitude $90^{\circ} \mathrm{E}$ between about $32^{\circ} \mathrm{S}$ and $10^{\circ} \mathrm{N}$, has a width of $50-100 \mathrm{~km}$ and rises an average $2 \mathrm{~km}$ above the surrounding ocean floor. The northern portion (to about $7^{\circ} \mathrm{S}$ ) is broken up into a series of en echelon blocks whereas in the south the ridge is straight and flat-topped. But the most conspicuous characteristic of the ridge - conspicuous by its absence, that is-. is its seismicity. Ninetyeast Ridge is commonly supposed to be a dormant fossil feature in the middle of the Indian-Australian plate. It is 'aseismic' in the sense that, unlike actively spreading ridges, it appears not to have associated with it frequent small earthquakes. Indeed, it is often cited as the archetypal aseismic ridge, the model for similar ridges elsewhere (for example, the Walvis Ridge in the south Atlantic).

But as Stein and Okal (J. geophys. Res. 83, 2233; 1978) now point out at some length, Ninetyeast Ridge is not aseismic at all. On the contrary, historically it has been associated with substantial seismicity. A new compilation of seismic data by Stein and Okal shows that since 1913 the region has seen four earthquakes with surface wave magnitudes $\left(M_{s}\right)$ greater than 7 , ten with $\mathrm{Ms}_{\mathrm{s}}$ in the range 6-7 and at least thirteen (and possibly as many as twenty-five) with body wave magnitudes $\left(m_{b}\right)$ in the range 5-6. When large earthquakes are taken into account Ninetyeast Ridge, far from being aseismic, is very highly seismic (although the southern section is much less so). Indeed, it is far more seismic than any spreading ridge and has a seismicity comparable to that of large transform fault systems (for example, the San Andreas fault). In terms of large earthquakes, only subduction zones are more seismic than Ninetyeast Ridge.

To Stein and Okal this can only mean that Ninetyeast Ridge is either an active plate boundary or a zone of

Peter J. Smith is Reader in the Department of Earth Sciences at the Open University. major intraplate deformation. In fact they opt for the latter on the basis of a study of earthquake mechanisms and bathymetry. It will come as no surprise to most Earth scientists to hear that the tectonics of the Ninetyeast Ridge area are as complex as those in any other part of the Indian Ocean. But briefly, and perhaps over simply, the portion of the ridge north of $10^{\circ} \mathrm{S}$ is the main active seismic zone, where both vertical and strike slip motion occur. The latter is left lateral along a roughly north-south plane and is associated with compression across the ridge. In this northern section the ridge zone thus has some transform faultlike characteristics, correlating roughly with that part of the ridge broken into irregular blocks. It is not a true transform fault, however, because the compression occurs over a broad zone rather than precisely along the ridge.

South of $10^{\circ} \mathrm{S}$, where the ridge is much smoother and much less seismic, the style of deformation differs on opposite sides of the ridge which itself remains largely undeformed. To the east normal faulting occurs, possibly related to the formation of a complex of ridges and graben-like troughs roughly parallel to the main ridge. These features suggest tensional deformation with tension in the NW-SE direction. To the west of the ridge, on the other hand, there seems to be NW-SE compression taking place largely aseismically. Here there is a complex terrain comprising NE-trending ridges and deeps. According to Stein and Okal this overall interpretation is generally consistent with the data and, if correct, implies that the Indian plate is currently undergoing substantial internal deformation with some relative motion between the Indian and Australian sides. In other words, the common assumption that the old Indian and Australian plates have been acting as a single plate for about the past 32 million years is not entirely valid.

Broadly it is as if the west (Indian) side of the plate is encountering resistance from the collision with Asia whereas the east (Australian) side is subducting smoothly at the Sumatra trench. The word 'broadly' is crucial here, however, for the detailed picture must be very complex indeed. Part of the difficulty in sorting it all out arises from the fact that the present geological pattern is not entirely the result of the present phase of tectonic activity but is partly a reflection of the ridge's much earlier history; current tectonic processes are only modifying a pre-existing structure. And this works both ways, of course. Stein and Okal claim that their results have no direct bearing on the question of the origin of Ninetyeast Ridge which has been variously regarded as a horst, the result of overriding plates, a consequence of excess volcanism, and the trace of a mantle plume. But they also claim that "a significant fraction of the morphology of the Ninetyeast Ridge is due to the present-day tectonics of the area". Clearly, therefore, those interested in the origin of Ninetyeast Ridge must be careful not to include in their interpretations features that have developed much more recently as part of the ongoing deformation identified by Stein and Okal.

\section{Halogenated hydrocarbon effects}

\section{from Alastair Hay}

IN the late $1960 \mathrm{~s}$, the polychlorinated biphenyls (PCBs) were recognised to be widespread industrial pollutants and to produce toxic symptoms in animals and man. They induce the skin condition chloracne, drug-metabolising enzymes, and porphyria and have immunosuppressive effects. Vos et al. (Food and Cosmetic Toxicol. 8,625 1970) were the first to report that commercial PCB formulations were contaminated with highly toxic polychorinated dibenzofuran (PCDF) impurities. This contamination, they suggested, could complicate interpretation of toxicity studies of PCBs. Many obervers now believe that it is these impurities which are responsible for differences reported in PCB toxicity studies. The PCBs, PCDFs and the polychlorinated dibenzodioxins (PCDDs) are all halogenated hydrocarbons and a meeting to review the toxic properties of this class of compounds was held recently in New York*.

Chemistry is central to any consideration of the biological properties of the halogenated hydrocarbons. Discussing the formation of the toxic polychlorinated dibenzodioxins (PCDDs) and polychlorinated dibenzofurans (PCDFs), C. Rappe (University of Umea, Sweden) reported on the numerous processes which generate these compounds. It is well known that the PCDDs are produced when trichlorophenates and pentachlorophenates are heated. Another source has recently been identified; the fly ash and flue gases of incinerators in several European cities contain both the PCDDs and PCDFs.

Rappe suggests that pyrolysis of the polychlorinated diphenylethers will also produce furans and that this ther-

* 'The International Conference on Health Effects of Halogenated Hydrocarbons' organised by the New York Academy of Sciences was held in New York from 24-27 June, 1978. 